\title{
The Magic Cube of eAccounting Instructional Design in Management Education
}

\author{
doi:10.3991/ijet.v4i2.860 \\ Silvia M. Pernsteiner, Michaela M. Schaffhauser-Linzatti and Regina Michalski-Karl \\ University of Vienna, Vienna, Austria
}

\begin{abstract}
This paper exemplifies the curricular framework of instructional design in management education at universities. The Magic Cube of eAccounting meets the didactical challenges concerning heterogeneous levels of preknowledge within large-scale accounting classes up to 600 -mostly nonnative speaking-undergraduate students. Following the Blended Learning approach, the presented pedagogical concept subsumes diverse subjects in the field of accounting and its inclusive adoption in continuative well as comprehensive courses. The applied methodology deals with these multidimensional impacts directed by a didactic rationale. The eLearning architecture shows a universally applicable design and may be customized. The eAccounting project was developed at the Faculty of Business, Economics and Statistics at the University of Vienna and has been implemented in 2008.
\end{abstract}

Index Terms-Blended Learning, Curriculum, Instructional Design, Learning Systems, Management Education.

\section{INTRODUCTION}

In 1999, the European Commission initiated the socalled Bologna-process to harmonize higher education at a supranational level and therefore foster a sustained panEuropean Higher Education Area (EHEA) [1]. The stipulated objectives explicitly include non-classical learning as well as teaching means and methodologies supported by innovative Information and Communication Technologies (ICT). Within the last decade numerous ventures that enable both, academic teaching and learning as well as scientific research independent of time and place have been installed to steadily build up a structured, constraint and innovative higher education architecture within the European Union.

\section{FRAMEWORK}

According to the implementation of e-Bologna the University of Vienna, Austria, dedicated its academic teaching strategies to the sustainable integration of e-Learning into the curricula and onto the corresponding didactical concepts [2]. In this context the university offers the Learning Management System (LMS) Frontier to provide e-Learning for about 72,000 students who are enrolled in currently 52 Bachelor Programs, 108 Master Programs, 7 Diploma Programs and $10 \mathrm{PhD}$ Programs. Until 2008, instead of Frontier the LMS Blackboard Vista has been in use.

Besides the commercial LMS, Moodle as alternative Open Source solution is applied as well.

At the Faculty of Business, Economics and Statistics accounting has been among the first subjects to introduce
e-Learning tools. After successfully completing a trial period of one academic year to test and evaluate basic online-applications and their students' acceptance within one single lecture, in 2007, the faculty established the socalled eAccounting project across several departments and chairs responsible for teaching accounting subjects.

\section{Problem SETting}

The core endeavors of the eAccounting scheme target the sustainable installation of a comprehensive, dynamic and customized e-Learning environment in the field of business sciences which is a tailor-made solution meeting several pedagogical challenges. The preconditions can be divided into two key aspects. They firstly comprise the individually composed structure of students participating in each single accounting lecture (further called external parameters). Secondly, they subsume the curricula and particular syllabi of accounting classes at the University of Vienna (further called internal parameters).

Whereas the curricula per se mark predetermined and irrevocable constant, the entity of students attending an accounting lecture can be identified as variable impact factor. However, monitoring the students' behavior over time has shown comparable characteristics.

\section{A. External Parameters}

To understand the students' structure from the very first beginning it is to mention that Austrian universities de jure are not allowed to limit the number of students (apart from very few exceptions, i.e., medicine). They are further not allowed to select their students but have to accept everybody for enrollment who has achieved his or her Alevels. Hence, the key aspects within the external parameters comprise the large number with up to 600 students attending every single accounting class each semester. The lecturers are urged to accept all students who do want to participate without any limits concerning the class size. This given condition implies that the instructional design allows nothing more than ex-cathedra teaching in classin other words: without Blended Learning there would not be much room for personal interaction between teacher and learners.

At the outset of the two year lasting development of eAccounting, a wide-ranging survey has been conducted to determine the students' specific preknowledge of management sciences with a special focus on accounting.

Furthermore, individual skills and qualifications such as familiarity with ICT as well as different learning preferences have been filtered to gear eAccounting to the special requirements right from the beginning and thus, meet the 
expectations as well as the pedagogical needs of undergraduate students in an appropriate way.

The online-questionnaire containing both quantitative and qualitative questions showed the following results: The typical audience is mainly composed of international students originally coming from over 50 countries. Most of these first-year students have hardly comparable highschools exams due to their dissimilar foreign education emphases which results in a serious heterogeneity in the preknowledge of accounting matters.

In addition, one third of the attendees don't have German as their mother tongues. All classes are taught in German and accounting per se also deals with language sensitive topics - such as legal regulations only available in German which can't be translated without language bias. This content-related focus on German language claims specific attention to design a customized VLE which regards these special requirements focusing the recipients' needs in an appropriate way.

The participants' knowledge of cultural techniques regarding ICT is wide ranged from having no experience with new media to quasi expert knowledge in using virtual learning instruments gained in high school.

\section{B. Internal Parameters}

eAccounting emphasizes the installation of applied eLearning instruments across both, obligatory as well as voluntary lectures offered by the Faculty of Business, Economics and Statistics at the University of Vienna.

In accordance to the structure designated within the Bologna process the faculty offers four baccalaureate studies for undergraduate students. These are business administration, international business administration, statistics, and economics. Additionally all studies at the University of Vienna are supported by elective modules in business administration, statistics, and economics. Besides, the classes included in eAccounting are still provided for the four old curricula not conform to the Bologna structure.

Figure 1 shows the bottom-up structure of accounting classes of all mentioned studies. Financial Accounting for Beginners (FA-B) and Cost Accounting for Beginners (CA-B) starting at level 0 (Pre-Training in Figure 2) are not part of the obligatory curricula and thus, not regarded as university level. eAccounting also includes the integration of pre-university elective courses which arises from the necessity to regulate the basic knowledge of the firstyear students (see explanation in A. External Parameters). As to say, these preparatory classes are offered to help every student without previous knowledge in financial accounting (FA) and cost accounting (CA), respectively,

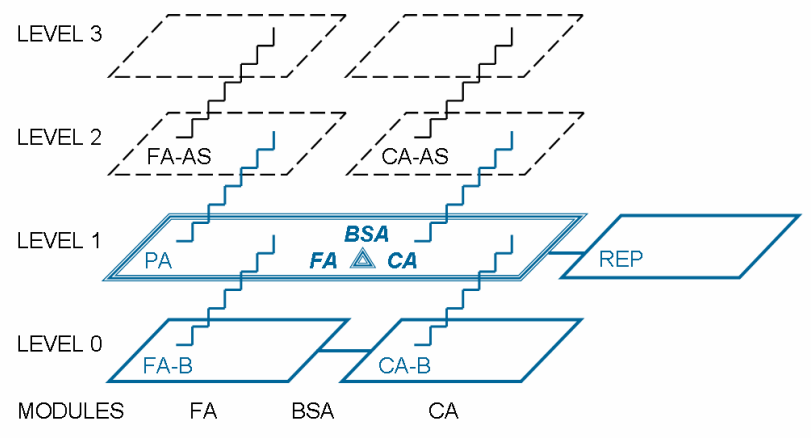

Figure 1. Curriculum. to prepare for the obligatory accounting class Principles of Accounting (PA) in level 1 (Beginners in Figure 2). The latter comprises subjects of Financial Accounting, Cost Accounting, and Balance Sheet Analysis (BSA), which is accompanied by a voluntary revision course (REP) to deepen the students' knowledge by offering training exercises. After passing the Principles of Accounting, the students are allowed to attend Financial Accounting for Advanced Students (FA-AS) as well as Cost Accounting for Advanced Students (CA-AS) at level 2 and consequently may elect major classes in financial and cost accounting.

eAccounting currently comprises the optional classes Financial Accounting for Beginners, Cost Accounting for Beginners, the compulsory Principles of Accounting, and its additional revision course. Notwithstanding, the created LMS is designed to integrate level 2 and level 3 classes at any time.

\section{The Magic Cube Of E-AcCounting}

The Magic Cube of eAccounting has been developed as tailored instructional design for large-scale lectures in management sciences. The concept aims at an enduring improvement of the individual learning performance of undergraduates by solving the heterogeneity concerning their prior knowledge.

Concurrently the differing language skills of students predominantly with an international background have to be taken into account. Although some detailed aspects of this problem setting have recently been discussed by case studies as in [3] or from an technological point of view the hereby presented multiplex diversities are not yet covered by experienced instructive concepts nor through already existing technical integrated solutions.

Figuring out appropriate e-Learning tools for largescaled classes in combination with providing the coexistence of different curricular levels and subject's subdisciplines simultaneously accumulates multi-faceted challenges for a convenient LMS.

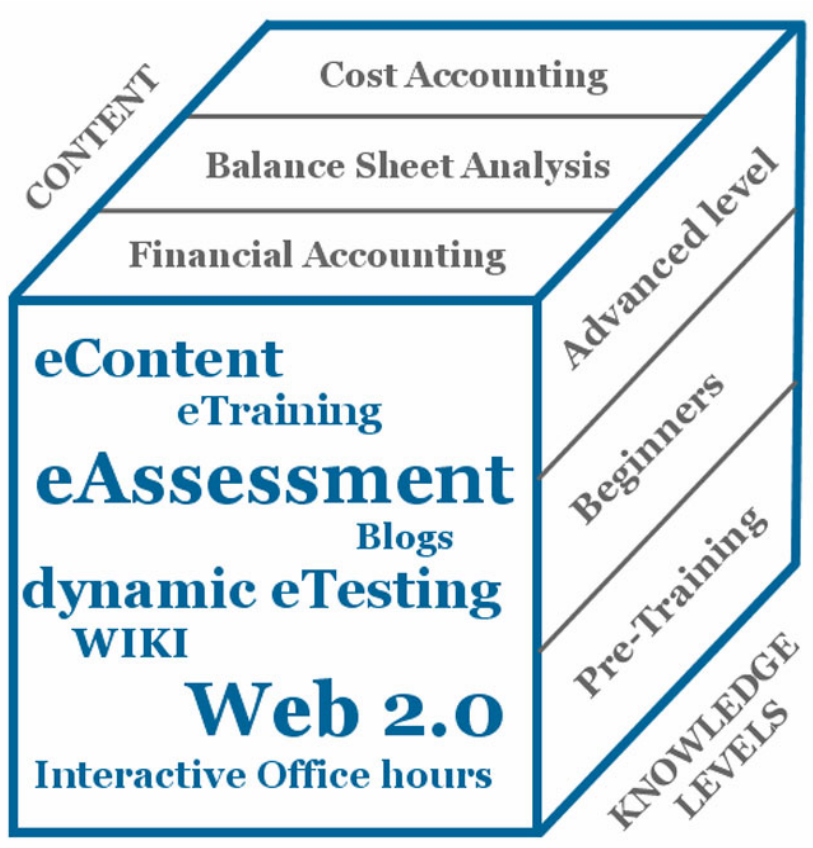

Figure 2. The Magic Cube of eAccounting. 
Among seven identified dimensions in different stages of the learning path and its individual progress are tightly meshed within the demonstrated three-dimensional problem setting. Acknowledging this, the Magic Cube of eAccounting has been developed to resolve of this nexus and to clearly arrange this multidimensional framework through establishing a teaching and learning management solution embedded in some multi-layer virtual learning architecture.

\section{A. Blended Learning}

The chosen instructional conception follows the Blended Learning approach by supporting the students' phases of attendance in classroom with extended online features. This course design gives an opportunity to "take the best of both worlds" as discussed in [4]. Reference [5] gives some clue about experience in Blended Learning with focus on accounting classes. The cultural impacts of e-Learning as discussed in [6] also occur in the previous experience.

eAccounting though allocates more than contextual deepening of content. By introducing superior navigation compliance through all subjects and accounting contents covered within, the sustainable didactic intercoordination continuously supplements the classroom lectures. Not only teaching aspects are embedded into the Blended Learning solution. eAccounting additionally merges academic record through combining examinations in class with eAssessment tools. Weekly e-Tests are conducted virtually and contain Multiple Choice Tests as well as short calculations. The results account for up to 30 percent of the final grade which gives the students extra incentives to routinely use and perform well at the LMS.

\section{B. Learning tools}

The developed eLearning scenarios subsume a variety of virtual learning instruments which include individually configurable learning path as well as cooperative learning tools. Besides content provision, integration of Web 2.0 oriented features like weblog and WIKIs to generate, elaborate, and collaboratively discuss subject matters, eAccounting shares applied e-Learning tools such as examinable e-Tests on a synchronous basis and optional self-tests. According to [7], these self-developed dynamic scripts and applications offer a customized interactive learning environment for the end-users and allow detailed tracking of the individual training process.

Whereas reference [8] outlines the e-Learning state of the art, reference [9] describes the students' perception of ICT. With a particular focus on the case of an accounting class, the perspective of learners using new technologies is highlighted. eAccounting also regards these essential considerations related to the recipients' point of view.

\section{Communication Instruments}

Distance learning includes more than just offering content provision together with a range of other online learning applications. It is indeed important for teachers and instructors to care about digital communication opportunities. eAccounting is designed as an integrating LMS which copes with the problems emerging due to the a priori phenomenon of large-scale classes. Thus, the students are accompanied within the virtual learning environment by a cross-linked virtual tutoring system.

To foster the communication process between both groups of communicators-between students and teacher on the one hand, and among the students on the other hand - the LMS offers a variety of synchronous and asynchronous communication tools. The hereby provided communication pool contains e-Mail, instant messaging, weblog, an online forum for organizational FAQs and moderated discussion groups dealing with accounting topics.

According to [10] and as a special service to deal with large-scale classes the students may participate in a weekly online-office hour where they can directly contact their lecturer and communicate simultaneously. All the chat protocols are published online afterwards, so that everybody can refer to the topics discussed.

\section{Benefits}

Beside interactive training and virtually elaborating accounting topics eAccounting enduringly improves the ICT skills of students. The universally applicable LMS can be customized and its comprehensive e-Learning architecture represents a dynamic driven teaching and learning surface directed by a pedagogic rationale. The core model of instructional design may be contextualized in-depth as well as additionally adjusted to the needs of the future audience at any time. Thus, the accounting classes at the Faculty of Business, Economics and Statistics benefit from distance learning efforts whereas the eAccounting project generates educationally sustained value added.

\section{LESSONS LEARNT AND FUTURE TRENDS}

First results of the evaluation after three semesters show an overall improvement in learning performance of the concerning accounting classes. This success can not only be demonstrated by better grading and less failures but also by an increasing learning motivation of the students. The participants of eAccounting engage more actively in e-Learning and have become aware that they are an active part of the lesson although they come to sit in a large-scale class of up to 600 students.

This observation might be the inauguration of a paradigm shift in meeting the a priori problems occurring within large-scale classes.

All the advantages concerning an improved learning performance outweigh possible drawbacks like humbling motivation to attend in-class lessons and a higher burden for teachers and students due to the increasing frequency of testing.

Hence, the eAccounting instructional design may be recommended as digital knowledge transfer solution for academic lectures with comparable problem settings-i.e., inhomogeneous students' knowledge and dissimilar language skills, mass lectures, comprehensive subjects, and different levels within university curricula.

\section{ACKNOWLEDGMENT}

The authors thank the Faculty of Business, Economics and Statistics at the University of Vienna for funding this research. 


\section{REFERENCES}

[1] Joint Declaration of the European Ministers of Education, The Bologna Declaration of 19 June 1999. http://www.bolognabergen2005.no/Docs/00-Main doc/990719 BOLOGNA DECLARATION.PDF (retrieval February 16, 2009).

[2] University of Vienna, Mission Statement. New Media in Teaching at the University of Vienna, 2004. http://elearningcenter.univie.ac. at/index.php?id=missionstatement (retrieval February 16, 2009).

[3] S. Sitchawat, "E-learning for Accounting Education in Thailand." in Proceedings of World Conference on Educational Multimedia, Hypermedia and Telecommunications 2005, P. Kommers \& G. Richards, Eds., Chesapeake, VA: AACE, 2005, pp. 110-115.

[4] Julija Lapuh Bele, Joze Rugelj, ,Blended learning - an opportunity to take the best of both worlds." in International Journal of Emerging Technologies in Learning (iJET), Vol. 2, No 3 (2007).

[5] J. Burgess, "Is a Blended Learning Approach Suitable for Mature, Part-time Finance Students?" in The Electronic Journal of e-Learning, Vol. 6, No. 2, 2008, pp. 131-138.

[6] M. Milani, "Cultural Impact on Online Education Quality Perception" The Electronic Journal of e-Learning, Vol. 6, No. 2, 2008, pp. 149-160.

[7] P. Blayney, "A Study of Management Accounting Rule Learning with Immediate Feedback Computer Assignments: The Effect of Providing Detailed Explanatory Feedback" in Proceedings of World Conference on Educational Multimedia, Hypermedia and Telecommunications, E. Pearson \& P. Bohma, Eds. Chesapeake, VA: AACE, 2006, pp. 2270-2275.
[8] E.K. Kahiigi, L. Ekenberg, H. Hansson, F. F. Tusubira and M. Danielson, "Exploring the e-Learning State of Art" in The Electronic Journal of e-Learning, Vol. 6, No. 2, 2008, pp. 77-88.

[9] A. Flynn, F. Concannon. and Ní Bheacháin, C. "Undergraduate Students' Perceptions of Technology-supported Learning: The Case of an Accounting Class" in International Journal on E-Learning, Vol. 4, No. 4, 2005, pp. 427-444.

[10] S. Borowicz, "The Effect of Synchronous Chat on Student Performance in an Undergraduate Introductory Accounting Course" in Proceedings of World Conference on E-Learning in Corporate, Government, Healthcare, and Higher Education 2004, G. Richards, Ed. Chesapeake, VA: AACE, 2004, pp. 1790-1793.

\section{AUTHORS}

Silvia M. Pernsteiner is with the Faculty of Business, Economics and Statistics, University of Vienna, 1210 Austria (silvia.pernsteiner@univie.ac.at).

Michaela M. Schaffhauser-Linzatti is with the Faculty of Business, Economics and Statistics, University of Vienna, 1210 Austria (michaela.linzatti@univie.ac.at).

Regina Michalski-Karl is with the Faculty of Business, Economics and Statistics, University of Vienna, 1210 Austria (regina.karl@univie.ac.at).

Manuscript received 25 February 2009. This paper was modified from a poster presentation at the International Conference of Interactive Computer Aided Learning ICL2008, September 24 - 26, 2008 in Villach, Austria. Published as submitted by the authors. 